\title{
Study of Dyslipidemia in Patients with Systemic Lupus Erythematosus and its Correlation to Disease Activity
}

\author{
Farag Khalil ${ }^{a}$, Mohamed Nabil Rafat ${ }^{a}$, Nader T. El- Beltagy ${ }^{a}$, Hassan A. Abdel Aziz Gaber ${ }^{b}$ \\ A internal Medicine Department, Faculty of Medicine, Al-Azhar University, Cairo, Egypt \\ ${ }^{\mathrm{B}}$ clinical Pathology Department, Faculty of Medicine, Al-Azhar University, Cairo, Egypt \\ Corresponding author:Farag Khalil, Email: dr.farag7070@azhar.edu.eg
}

\begin{abstract}
:
Background: Cardiovascular events and accelerated atherosclerosis in patients with active systemic lupus erythematosus results in significant increased morbidity and mortality. The non-traditional risk factors induce alteration in lipoprotein metabolism and the constant inflammatory and immune activity can lead to accelerated atherosclerosis. Aim: To assess prevalence of dyslipidemia in systemic lupus erythematosus patients and to study the relation of dyslipidemia to disease activity. Patients and methods: The presented study included 60 SLE adult patients (56 females and 4 males) and they were classified according to disease activity into two groups: Active Lupus: Included 30 lupus patients. Inactive Lupus: Included 30 lupus patients. 20 healthy subjects with matched age, sex and BMI were included as healthy controls. Methods: Patients underwent clinical assessment. Total cholesterol, (LDL, HDL) and triglyceride were measured.

Results: Cholesterol, LDL, and TG levels were elevated in the active group compared to that in the inactive group and healthy controls. This elevation was significant $(\mathrm{P}<0.001)$. But HDL level decreased in the active group compared to the inactive and healthy controls groups. The decrease of HDL was the active group is significant $(\mathrm{P}<0.001)$. Conclusion: The elevated levels of Total cholesterol, LDL, and TG and decreased level of HDL in SLE patients are considered an independent risk factor for cardiovascular disease. The dyslipidemia and inflammatory process predispose to premature atherosclerosis and disease activity contribute to dyslipidemia and hence cardiovascular risk associated with SLE.
\end{abstract}

Keyword: SLE, Dyslipidemia, Cholesterol, TG

\section{Introduction:}

Systemic lupus erythematous (SLE) is an autoimmune, chronic, relapsing, inflammatory, and often multi-systemic disorder of connective tissue, characterized by involvement of the skin, joint, kidney and serosal membranes ${ }^{(1)}$.

Patients with SLE have higher mortality and morbidity rate compared to general population. The major causes of death remain to be infection, lupus nephritis (LN), and cardiovascular disease (CVD) ${ }^{(2)}$.

CVD in autoimmune rheumatic diseases is caused by traditional (increasing age, male gender, hypertension, smoking, hypercholesterolemia, diabetes) and the socalled non-traditional risk factors ${ }^{(3)}$. There are statistically significant increases in coronary heart disease and stroke in SLE patients that cannot be fully explained by Framingham risk factors ${ }^{(3)}$. These non-traditional factors are disease related, such as disease activity, glucocorticoid, hydroxychloroquine (HCQ) used to control disease activity, impaired renal function, presence of antiphospholipid antibodies, and immune cell activation. A modification of Framingham risk score, where each item is multiplied by two, estimates more accurately the risk for coronary artery disease in lupus patients ${ }^{(3)}$.

Additional mortality in SLE patients shows a bimodal pattern, with an early peak due to the consequence of active lupus and a later peak attributable mainly to atherosclerosis ${ }^{(4)}$.

Abnormal plasma concentration of lipids is common in patients with SLE. Dyslipidemia usually refers to elevated total cholesterol (TC), triglycerides (TG), lowdensity lipoprotein (LDL), and decreased highdensity lipoprotein (HDL) level ${ }^{(4)}$.

Lupus nephritis (LN), a common and potentially life-threatening manifestation of SLE, occurs in almost half of the lupus patients ${ }^{(5)}$. Patients with LN have a higher TC, TG, and LDL and lower HDL and 
apolipoprotien B levels, than patients without renal manifestation ${ }^{(6)}$.

Dyslipidemia is more severe in lupus nephritic patients than those with a similar degree of chronic kidney disease despite disease inactivity, low level of proteinuria, and low dose steroid usage ${ }^{(7)}$. Hyperlipidemia can affect all parts of the nephron causing endothelial cell injury, glomerular filtration defect with hyperfiltration and tubuleinterstitial lipid deposition ${ }^{(7)}$.

If other systemic disorders such as diabetes mellitus and thyroiditis are also present, they can also cause changes in lipid metabolism. Age-related and postmenopausal changes also matter ${ }^{(8)}$.

Several mechanisms have been proved or suggested among factors that may increase risk of dyslipidemia in SLE and by turn increase risk of CVD. Interestingly, immune and inflammatory reactions seem to have a role in the pathogenesis of atherosclerotic vascular damage ${ }^{(9)}$. This raises the exciting possibility that SLE itself may be atherogenic through chronic activation of the immune system and inflammatory process. In fact, autoantibodies such as anti-phospholipid, antib2-glycoprotein1, anti-ox- LDL-c and antilipoprotein lipase and elevated inflammatory markers such as CRP and IL-6 are common finding of SLE. It is therefore reasonable to postulate that the interaction of disease associated factors induce specific alteration in lipoprotein metabolism which is aggravated by drugs and associated conditions frequently observed in lupus patients ${ }^{(9)}$.

Subjects and methods

The presented study included 60 SLE adult patients (56 females and 4 males) selected from Internal Medicine Departments and Rheumatology outpatient Clinic of Al-Hussein University Hospitals between May 2017 and January 2018. Twenty healthy subjects with matched age, sex and BMI were included as healthy controls.

Patients were classified according to disease activity into the following groups:

Active Lupus: Comprised 30 lupus patients.

Inactive Lupus: Comprised 30 lupus patients.

Methods:
Patients were subjected to full medical history taking, clinical examination, as well as laboratory investigations. The revised criteria of the American College of Rheumatology ${ }^{(10)}$. Were used for diagnosis of SLE.

Assessment of Disease Activity of SLE Patients:

The Systemic Lupus Activity Measure (SLAM) index was recorded for each patient. This scoring system is based on a comparative study done by Liang and his colleagues ${ }^{(\mathbf{1 0})}$.

The Lupus Activity Index is a concise measure comprised of a 0-3 visual analog scale for 4 symptoms (fatigue, rash, joint involvement, serositis) and 4 signs (neurologic, renal, pulmonary, and hematologic involvement).

All subjects were subjected to

A- Detailed history taking.

B- Full clinical examination.

C- Routine laboratory investigations; erythrocyte sedimentation rate (ESR), Creactive protein (CRP), fasting and 2 hours postprandial blood glucose, complete blood count (CBC), complete urine analysis, and liver and kidney function test.

D- Measurement of proteins in 24 hour urine (g/24hrs).

E- Antinuclear antibodies (ANA) and Antidouble stranded deoxyribonucleic acid antibodies (anti-dsDNA. Done by immunofluorescence technique. Titer of $1 / 40$ or more is considered positive. (Done for SLE patients only).

F-Serum complement levels (C3, C4). Done by nephelometry (Normal level of C3 is 84$160 \mathrm{mg} / \mathrm{dl}$ and for C4 12- $36 \mathrm{mg} / \mathrm{dl}$ ): (Done for SLE patients only)

G-Total cholesterol in $\mathrm{mg} / \mathrm{dl}$ by enzymatic colometric assay. H-Total triglyceride in $\mathrm{mg} / \mathrm{dl}$ by enzymatic colometric assay. J-LDL cholesterol by $\mathrm{mg} / \mathrm{dl}$ by enzymatic colometric assay. K-HDL in $\mathrm{mg} / \mathrm{dl}$ by enzymatic colometric assay.

Sample collections: After 12 hours fast $8 \mathrm{ml}$ venous blood was obtained from all participate.

They were divided into; $1 \mathrm{ml}$ on EDTA (1 $\mathrm{mg} / \mathrm{ml}$ ) for $\mathrm{CBC}, 5 \mathrm{ml}$ into plain tubes and serum samples were separated into 2 aliquots for investigations.

Serum total cholesterol, triglycerides, and HDL-c concentration were measured ${ }^{(11)}$. The 
material was supplied by Spinreact (Spain) for total cholesterol and triglycerides and by STANBIO (USA) for HDL-c. LDL-c concentration was calculated ${ }^{(\mathbf{1 2})}$.

\section{Statistical analysis:}

Statistical Package for Social Science (SPSS) version 17was used. Quantitative data were expressed as mean \pm SD and qualitative data were expressed as number and percentage of the total. The mean and standard deviation
(SD) were calculated. Comparing the mean \pm $\mathrm{SD}$ of 2 groups was done using the unpaired $\mathrm{t}$ test. Determining the extent that a single observed series of proportions differs from a theoretical or expected distribution was done using the Chi square test. Receiver operator characteristic (ROC) curve was used and sensitivity and specificity for various cut off points were plotted. $\mathrm{P}$ was considered nonsignificant if $>0.05$, significant if $<0.05$ and highly significant if $<0.01$ and $<0.001$.

\section{Results}

Table (1): Cholesterol level among the studied groups

\begin{tabular}{|c|c|c|c|c|c|c|c|}
\hline \multirow{2}{*}{ Groups } & \multicolumn{5}{|c|}{ Cholesterol (mg/dl) } & \multicolumn{2}{|c|}{ ANOVA } \\
\hline & \multicolumn{2}{|c|}{ Range } & \multirow{2}{*}{\begin{tabular}{|l|l|} 
Mean \\
272.767
\end{tabular}} & \multicolumn{2}{|c|}{ \pm SD } & \multirow{4}{*}{$\begin{array}{l}\mathbf{F} \\
16.544\end{array}$} & P-value \\
\hline Active group & 146 & -376 & & \pm & 58.533 & & \multirow{3}{*}{$<0.001 *$} \\
\hline Inactive group & 165 & $-\quad 324$ & 249.767 & \pm & 46.804 & & \\
\hline Control group & 156 & 265 & 194.100 & \pm & 26.213 & & \\
\hline \multicolumn{8}{|l|}{$\begin{array}{l}\text { TUKEY'S Test } \\
\end{array}$} \\
\hline A\&I & & \multicolumn{2}{|c|}{$\mathrm{A \& C}$} & & \multicolumn{3}{|c|}{ I\&C } \\
\hline 0.156 & & \multicolumn{2}{|c|}{$<0.001 *$} & & \multicolumn{2}{|c|}{$<0.001^{*}$} & \\
\hline
\end{tabular}

$\mathbf{A} \boldsymbol{\&} \mathbf{I}=$ active and inactive, $\mathbf{A} \boldsymbol{\&} \mathbf{C}=$ active and control, $\mathbf{I} \boldsymbol{\&} \mathbf{C}=$ inactive and control

Table 1 shows that cholesterol level is elevated in active group compared to that in inactive group and healthy controls. This elevation is significant $(P<0.001)$.

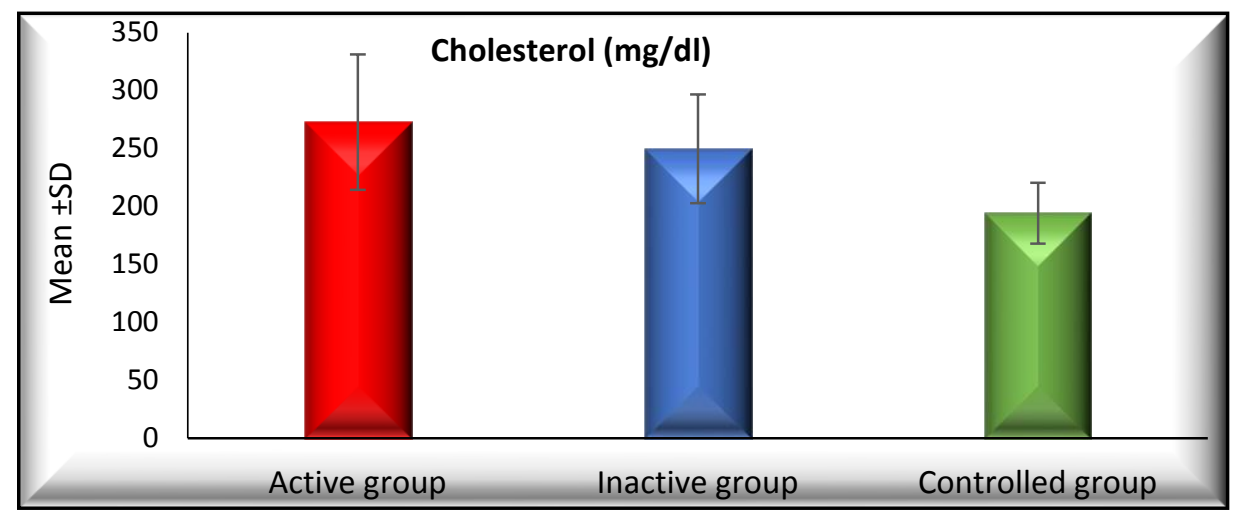

Fig (1): Shows the correlation between cholesterol levels in active, inactive, and healthy controls.

Table (2): TG level among the studied groups

\begin{tabular}{|c|c|c|c|c|c|c|c|}
\hline \multirow{2}{*}{ Groups } & \multicolumn{5}{|c|}{ TG (mg/dl) } & \multicolumn{2}{|c|}{ ANOVA } \\
\hline & \multicolumn{2}{|c|}{ Range } & \multirow{2}{*}{$\begin{array}{l}\text { Mean } \\
271.300\end{array}$} & \multirow{2}{*}{ \pm} & SD & \multirow[t]{2}{*}{$\mathbf{F}$} & \multirow[t]{2}{*}{ P-value } \\
\hline Active group & 105 & 388 & & & 91.306 & & \\
\hline Inactive group & 135 & 382 & 246.133 & \pm & 76.325 & \multirow[t]{2}{*}{19.891} & \multirow[t]{2}{*}{$<0.001 *$} \\
\hline Control group & 126 & 168 & 142.100 & \pm & 11.534 & & \\
\hline \multicolumn{8}{|l|}{ TUKEY'S Test } \\
\hline A\&I & & \multirow{2}{*}{\multicolumn{2}{|c|}{$\frac{\mathbf{A} \& \mathbf{C}}{<0.001^{*}}$}} & & \multicolumn{3}{|c|}{ I\&C } \\
\hline 0.383 & & & & & \multicolumn{3}{|c|}{$<0.001^{*}$} \\
\hline
\end{tabular}

$\mathbf{A} \boldsymbol{\&} \mathbf{I}=$ active and inactive, $\mathbf{A \& C}=$ active and control, $\mathbf{I} \mathbf{\&} \mathbf{C}=$ inactive and control

Table 2 shows that TG level is elevated in active group compared to that in inactive and healthy controls groups. This elevation is significant $(\mathrm{P}<0.001)$. 


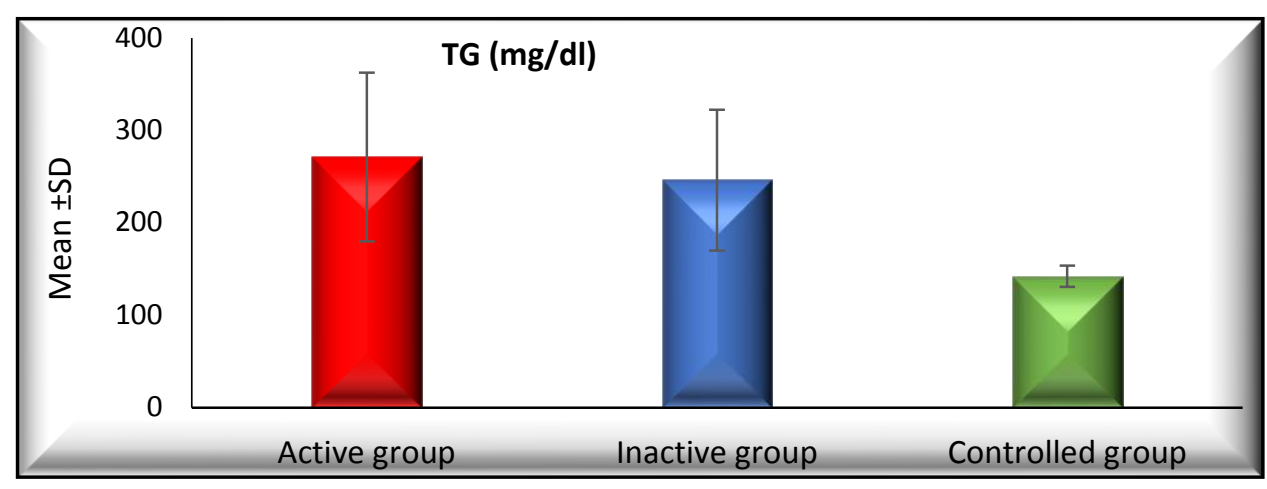

Figure (2): Shows the correlation between TG level in active, inactive, and healthy controls groups.

Table (3): LDL level in the active group compared to that in the inactive and healthy controls groups.

\begin{tabular}{|c|c|c|c|c|c|c|c|}
\hline \multirow{2}{*}{ Groups } & \multicolumn{5}{|c|}{ LDL (mg/dl) } & \multicolumn{2}{|c|}{ ANOVA } \\
\hline & \multicolumn{2}{|c|}{ Range } & \multirow{2}{*}{$\begin{array}{l}\text { Mean } \\
146.233 \\
\end{array}$} & \multirow{2}{*}{$\begin{array}{l} \pm \\
\pm\end{array}$} & SD & \multirow{4}{*}{$\begin{array}{l}\mathbf{F} \\
13.277\end{array}$} & \multirow{4}{*}{$\begin{array}{l}\text { P-value } \\
<0.001 *\end{array}$} \\
\hline Active group & 79 & 188 & & & 30.450 & & \\
\hline Inactive group & 69 & $-\quad 187$ & 136.500 & \pm & 33.558 & & \\
\hline Control group & 66 & 149 & 101.900 & \pm & 25.470 & & \\
\hline \multicolumn{8}{|l|}{ TUKEY'S Test } \\
\hline A\&I & & \multicolumn{2}{|c|}{ A\&C } & & \multicolumn{3}{|c|}{ I\&C } \\
\hline 0.437 & & \multicolumn{2}{|c|}{$<0.001 *$} & & \multicolumn{3}{|c|}{$0.001 *$} \\
\hline
\end{tabular}

$\mathbf{A} \boldsymbol{\&} \mathbf{I}=$ active and inactive, $\mathbf{A} \boldsymbol{\&} \mathbf{C}=$ active and control, $\mathbf{I} \mathbf{\&} \mathbf{C}=$ inactive and control.

Table 3 shows that LDL level is elevated in active group compared to that in inactive and healthy controls groups. This elevation in active group is significant $(\mathrm{P}<0.001)$.

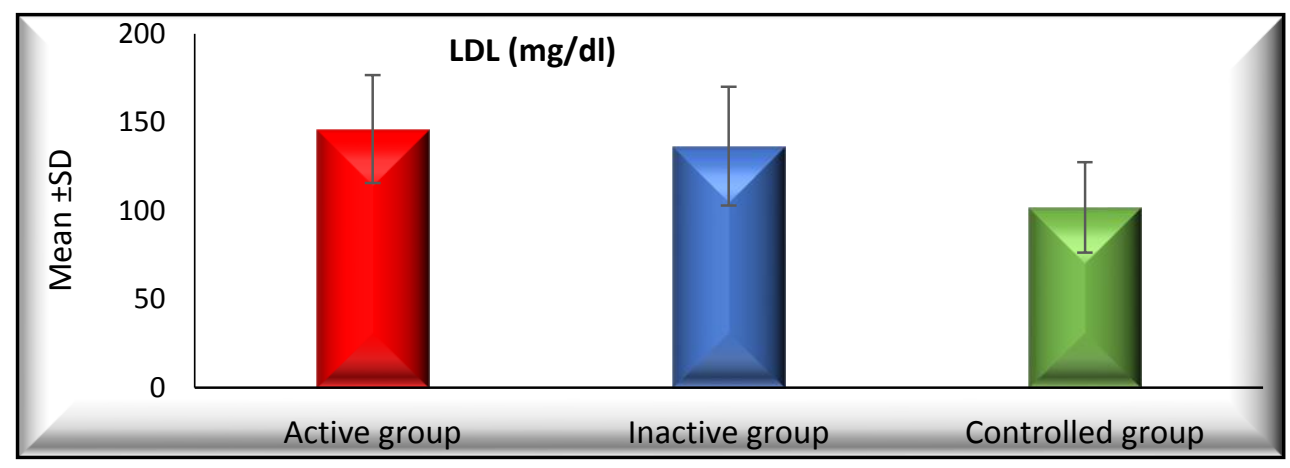

Figure (3): Shows the between LDL levels in active, inactive, and healthy controls groups.

Table (4): HDL level in the active group compared to that in the inactive and healthy controls groups.

\begin{tabular}{|c|c|c|c|c|c|c|c|}
\hline \multirow{2}{*}{ Groups } & \multicolumn{5}{|c|}{ HDL (mg/dl) } & \multicolumn{2}{|c|}{ ANOVA } \\
\hline & \multicolumn{2}{|c|}{ Range } & \multirow{2}{*}{$\begin{array}{l}\text { Mean } \\
35.800 \\
\end{array}$} & \multicolumn{2}{|c|}{ \pm SD } & \multirow{4}{*}{$\begin{array}{l}\mathbf{F} \\
15.976\end{array}$} & \multirow{4}{*}{$\begin{array}{l}\text { P-value } \\
<0.001^{*}\end{array}$} \\
\hline Active group & 19 & 57 & & \pm & 11.146 & & \\
\hline Inactive group & 24 & -73 & 42.200 & \pm & 14.880 & & \\
\hline Control group & 38 & 77 & 56.500 & \pm & 11.533 & & \\
\hline \multicolumn{8}{|l|}{ TUKEY'S Test } \\
\hline A\&I & & \multicolumn{3}{|c|}{$\mathrm{A \& C}$} & \multicolumn{3}{|c|}{ I\&C } \\
\hline 0.134 & & \multicolumn{2}{|c|}{$<0.001 *$} & & \multicolumn{3}{|c|}{$0.001 *$} \\
\hline
\end{tabular}

$\mathbf{A} \boldsymbol{\&} \mathbf{I}=$ active and inactive, $\mathbf{A} \boldsymbol{\&} \mathbf{C}=$ active and control, $\mathbf{I} \mathbf{E} \mathbf{C}=$ inactive and control.

Table 4 shows that HDL level is decreased in active group compared to that in inactive and healthy controls groups. This decrease in active group is significant $(\mathrm{P}<0.001)$. 


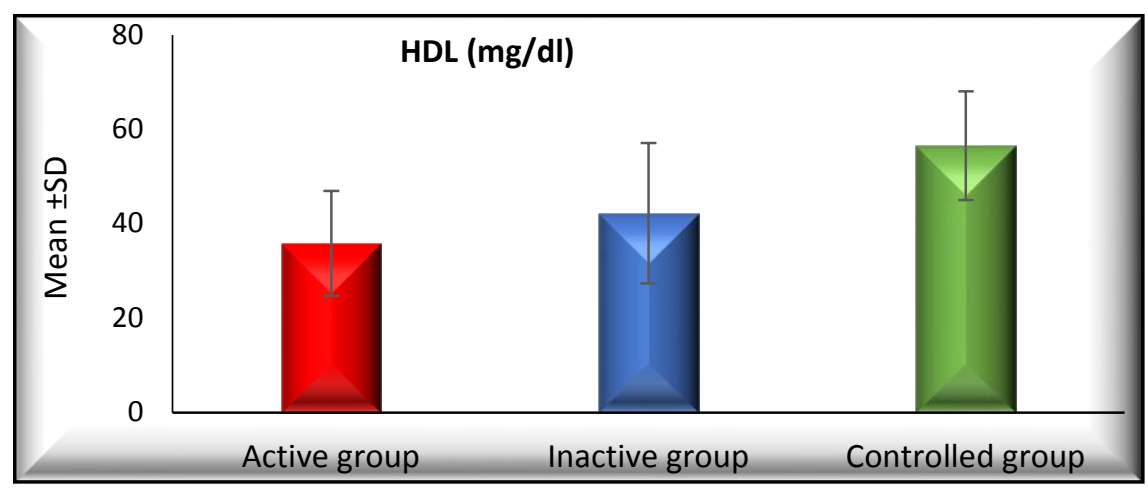

Figure (4): Shows the correlation between HDL levels in active, inactive, and healthy controls groups.

Table (5): CRP level in the active group compared to that in the inactive and healthy controls groups.

\begin{tabular}{|c|c|c|c|c|c|c|c|}
\hline \multirow{2}{*}{ Groups } & \multicolumn{5}{|c|}{ CRP (mg/l) } & \multicolumn{2}{|c|}{ ANOVA } \\
\hline & \multicolumn{2}{|c|}{ Range } & Mean & \multirow{2}{*}{ \pm} & SD & $\mathbf{F}$ & P-value \\
\hline Active group & 11 & 42 & 23.633 & & 7.622 & \multirow{3}{*}{123.903} & \multirow{3}{*}{$<0.001 *$} \\
\hline Inactive group & 3 & 9 & 6.067 & \pm & 1.780 & & \\
\hline Control group & 4 & 9 & 5.800 & \pm & 1.508 & & \\
\hline \multicolumn{8}{|l|}{ TUKEY'S Test } \\
\hline A\&I & & \multirow{2}{*}{\multicolumn{2}{|c|}{$\begin{array}{l}\mathbf{A \& C} \\
<0001 *\end{array}$}} & & \multicolumn{3}{|c|}{$I \& C$} \\
\hline$<0.001 *$ & & & & & \multicolumn{3}{|c|}{0.980} \\
\hline
\end{tabular}

$\mathbf{A} \boldsymbol{\&} \mathbf{I}=$ active and inactive, $\mathbf{A} \boldsymbol{\&} \mathbf{C}=$ active and control, $\mathbf{I} \boldsymbol{\&} \mathbf{C}=$ inactive and control.

Table 5 shows that CRP level is elevated in active group compared to that in inactive and healthy controls groups. This increase in CRP level in active group is significant $(\mathrm{p}<0.001)$.

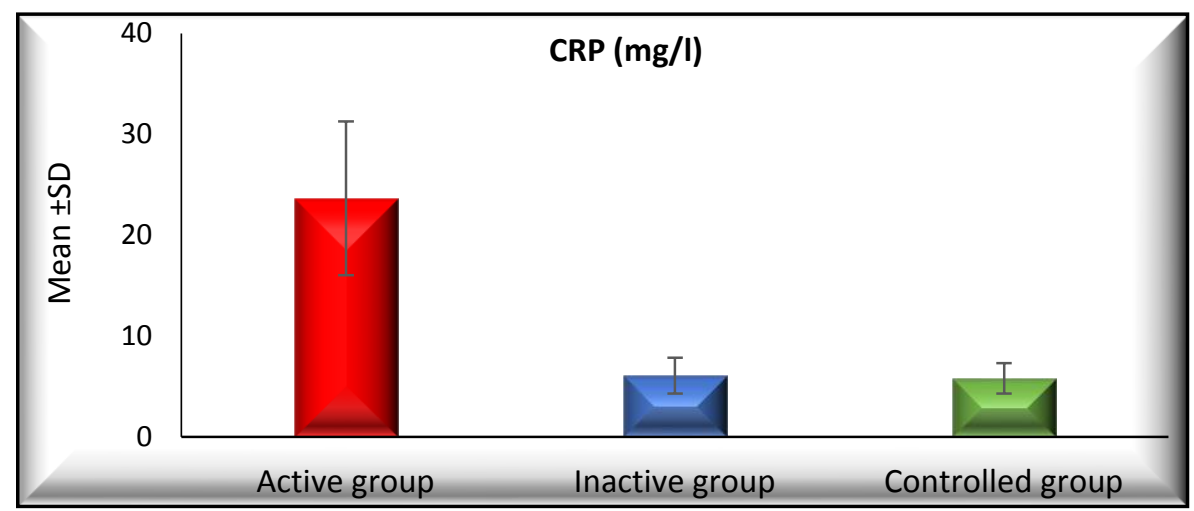

Figure (5): Shows the correlation between CRP levels in active, inactive, and healthy controls groups.

Table (6): C3 level in the active group compared to that in the inactive and healthy controls groups.

\begin{tabular}{|c|c|c|c|c|c|c|c|}
\hline \multirow{2}{*}{ Groups } & \multicolumn{5}{|c|}{ C3 (mg/dl) } & \multicolumn{2}{|c|}{ ANOVA } \\
\hline & \multicolumn{2}{|c|}{ Range } & \multirow{2}{*}{$\begin{array}{l}\text { Mean } \\
74.200 \\
\end{array}$} & \multirow{2}{*}{$\begin{array}{l} \pm \\
\pm\end{array}$} & SD & \multirow[t]{2}{*}{ F } & \multirow[t]{2}{*}{ P-value } \\
\hline Active group & 50 & - 110 & & & 13.345 & & \\
\hline Inactive group & 94 & -188 & 144.933 & \pm & 29.496 & \multirow[t]{2}{*}{78.891} & \multirow[t]{2}{*}{$<0.001 *$} \\
\hline Control group & 93 & $\begin{array}{l}-\quad 165 \\
\end{array}$ & 124.400 & \pm & 20.314 & & \\
\hline \multicolumn{8}{|l|}{ TUKEY'S Test } \\
\hline A\&I & & \multicolumn{2}{|c|}{ A\&C } & & \multicolumn{2}{|c|}{ I\&C } & \\
\hline$<0.001 *$ & & \multicolumn{2}{|c|}{$<0.001 *$} & & \multicolumn{2}{|c|}{$0.006^{*}$} & \\
\hline
\end{tabular}

$\mathbf{A} \boldsymbol{\&} \mathbf{I}=$ active and inactive, $\mathbf{A} \boldsymbol{\&} \mathbf{C}=$ active and control, $\mathbf{I} \mathbf{\&} \mathbf{C}=$ inactive and control.

Table 6 shows that $\mathrm{C} 3$ level is decreased in active group compared to that in inactive and healthy controls groups. This decrease in $\mathrm{C} 3$ level in active group is significant $(\mathrm{P}<0.001)$. 


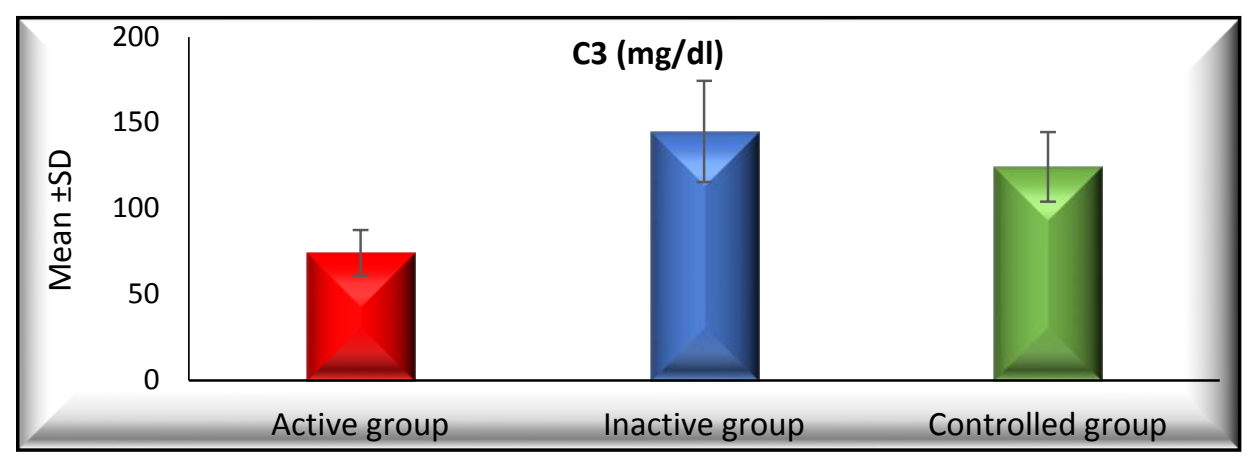

Figure (6): Shows the correlation between C3 levels in active, inactive, and healthy controls groups. Table (7): C4 level in the active group compared to the inactive and healthy controls groups.

\begin{tabular}{|c|c|c|c|c|c|c|c|}
\hline \multirow{2}{*}{ Groups } & \multicolumn{5}{|c|}{ C4 (mg/dl) } & \multicolumn{2}{|c|}{ ANOVA } \\
\hline & \multicolumn{2}{|c|}{ Range } & \multirow{2}{*}{$\begin{array}{l}\text { Mean } \\
9.267 \\
\end{array}$} & \multirow{2}{*}{$\begin{array}{l} \pm \\
\pm\end{array}$} & SD & \multirow{4}{*}{$\begin{array}{l}\mathbf{F} \\
46.451\end{array}$} & \multirow{4}{*}{$\begin{array}{l}\text { P-value } \\
<0.001 *\end{array}$} \\
\hline Active group & 5 & 16 & & & 2.924 & & \\
\hline Inactive group & 10 & 39 & 25.533 & \pm & 8.361 & & \\
\hline Control group & 12 & 38 & 24.200 & \pm & 9.146 & & \\
\hline \multicolumn{8}{|l|}{ TUKEY'S Test } \\
\hline A\&I & & \multicolumn{3}{|c|}{ A\&C } & \multicolumn{3}{|c|}{ I\&C } \\
\hline$<0.001 *$ & & \multicolumn{2}{|c|}{$<0.001 *$} & & \multicolumn{3}{|c|}{0.792} \\
\hline
\end{tabular}

$\mathbf{A} \boldsymbol{\&} \mathbf{I}=$ active and inactive, $\mathbf{A \& C}=$ active and control, $\mathbf{I} \boldsymbol{\&} \mathbf{C}=$ inactive and control.

Table 7 shows that $\mathrm{C} 4$ level is decrease in active group compared to inactive and healthy controls groups. This decrease in $\mathrm{C} 4$ level in active group is

Table (8): Platelet level in the active group compared to the inactive and healthy controls groups.

\begin{tabular}{|c|c|c|c|c|c|c|c|}
\hline \multirow{2}{*}{ Groups } & \multicolumn{5}{|c|}{ Platelet (x1000) } & \multicolumn{2}{|c|}{ ANOVA } \\
\hline & \multicolumn{2}{|c|}{ Range } & \multirow{2}{*}{$\begin{array}{l}\text { Mean } \\
92.633\end{array}$} & \multirow{2}{*}{ \pm} & SD & \multirow[t]{2}{*}{$\mathbf{F}$} & \multirow[t]{2}{*}{ P-value } \\
\hline Active group & 71 & 120 & & & 12.439 & & \\
\hline Inactive group & 103 & $-\quad 198$ & 140.567 & \pm & 21.847 & 135.464 & $<0.001 *$ \\
\hline Control group & 165 & 410 & 271.700 & \pm & 70.345 & & \\
\hline \multicolumn{8}{|l|}{ TUKEY'S Test } \\
\hline A\&I & & \multicolumn{3}{|c|}{ A\&C } & \multicolumn{3}{|c|}{ I\&C } \\
\hline$<0.001 *$ & & \multicolumn{2}{|c|}{$<0.001 *$} & & \multicolumn{3}{|c|}{$<0.001 *$} \\
\hline
\end{tabular}

$\mathbf{A} \boldsymbol{\&} \mathbf{I}=$ active and inactive, $\mathbf{A} \boldsymbol{\&} \mathbf{C}=$ active and control, $\mathbf{I} \boldsymbol{\&} \mathbf{C}=$ inactive and control.

Table 8 shows that platelet level is decreased in active group compared to inactive and healthy controls groups. The decrease level of platelet in active group is significant $(\mathrm{P}<0.001)$.

\section{Discussion}

Patients with SLE have higher mortality and morbidity rate compared to the general population. The major causes of death remain to be infection, lupus nephritis (LN), and cardiovascular disease (CVD) ${ }^{(3)}$.

There is increased cardiovascular mortality in SLE. Accelerated atherosclerosis leading to coronary artery disease (CAD) and other cardiac manifestations have increasing importance for the management and outcome of SLE. Several traditional and disease-related risk factors, as well as corticosteroids are suggested to be involved in lupus-associated atherosclerosis and its clinical manifestations (3).

Traditional risk factors, such as altered lipid levels, aging and smoking, do not fully explain this increased risk of CVD, and strongly suggesting that autoimmunity contributes to accelerated atherosclerosis ${ }^{(3)}$.

Altered immune system function is recognized as the primary contributor to both the initiation and progression of atherosclerosis. Many mechanisms of autoimmunity, including changes in cytokine 
levels and innate immune responses, autoantibodies, dysfunctional lipids, and oxidative stress, could heighten atherosclerotic risk. In addition, multiple SLE therapeutics seems to affect the development and progression of atherosclerosis both positively and negatively ${ }^{(\mathbf{1 3})}$.

The aim of this study was to evaluate the plasma lipid (cholesterol, HDL, LDL, and triglyceride) and its relation to systemic lupus erythematosus activity.

The present study revealed elevated levels of serum TG, LDL and $\mathrm{TC}$ in active group compared to that revealed in the inactive group or healthy control. This elevation was statistically highly significant $(\mathrm{P}<0.001)$.

Also, the study revealed decreased serum HDL level in the active group compared to that the in inactive group or healthy controls. The degree of decreased HDL level is significant $(\mathrm{P}<0.001)$.

The findings in the current study are ongoing with general consensus of the so called "Lupus pattern" of dyslipoproteinemia which defined by elevated levels of TC, LDL and TG, and lower HDL levels ${ }^{(\mathbf{1 4})}$.

Lupus pattern is reported to be associated with atherosclerotic risks ${ }^{(\mathbf{1 5})}$.

The findings in active lupus group in this study are supported by several previous studies ${ }^{(\mathbf{1 6}-19)}$ and one study ${ }^{(7)}$ demonstrated that increased expression of TGs and low levels of HDL (lupus dyslipidemia) were associated with disease activity in SLE and suggested their use as markers of disease activity.

Dyslipoproteinemia in lupus patients are attributed to various etiologies. Autoimmunity and inflammation are among players ${ }^{(9)}$.

It seems reasonable to accept that inflammatory conditions of the disease itself would induce specific alterations in the lipid profile. It is known that TNF-Alfa which presents in a high concentration in SLE patients; promote a significant increase in circulating TG due to increase hepatic synthesis of VLDL. In addition; TNF has the ability to inhibit LPL ${ }^{(16)}$.

The production of a large variety of autoantibodies is a prominent pathogenic feature of SLE and it had been proved that it lead to autoimmune hyperlipidemia. The binding of autoantibodies to LPL impair its enzymatic activity, and titers of anti-LPL antibody correlate with TG levels, disease activity, and markers of inflammation ${ }^{(9)}$.
Chronic activation or damage to endothelium in SLE may trigger the inflammatory cascade and thereby promote atherogenesis. Several forms of endothelial insult are being recognized in SLE, including hypercholesterolemia, hyperhomocysteinemia, mechanical stress from hypertension, increased oxidative stress and immunologic injury as a result of immune complex deposition ${ }^{(20)}$.

In contrast to the findings of the current study; some other studies ${ }^{(21,22)}$ reported relatively low LDL, low HDL, high VLDL, and high TG levels. They attributed these finding to impaired LPL activity which degrades VLDL, with subsequent conversion to LDL. Also Das reported high levels of VLDL and TG and low level of HDL in inactive lupus patients and decrease in LDL during active disease, the so called "active lupus pattern", suggesting a defect in VLDL metabolism ${ }^{(23)}$.

Determinations of serum anti-ds DNA titter and complement levels $(\mathrm{C} 3, \mathrm{C} 4)$ are the most common and useful tests for assessment of disease activity and predicting flares in SLE.

The current work demonstrated a significant increase in anti-dsDNA antibodies levels in active SLE patients in comparison to patients in remission. Anti-dsDNA and anti-Sm antibodies are highly specific for idiopathic SLE. Combination of anti-dsDNA, serum complements $\mathrm{C} 3$ and $\mathrm{C} 4$, ESR and CRP supported by relevant tissue histology, probably provides the most useful information on disease activity, particularly in patients with lupus nephritis. However, results of any laboratory test should always be interpreted with reference to the clinical presentation ${ }^{(24)}$. The present study show that there was a statistically significant difference between active and inactive SLE patients regarding anti-ds DNA levels, which agrees with (AbdElsamad et al., 2000 ${ }^{(25)}$.

However some authors observed that raised anti-dsDNA titer is of no significance and may be found raised in quiescent diseases ${ }^{(26)}$.

In the present study there was a statistically significant difference between the active group and inactive group with SLE as regarding serum complement $(C 3)$ level $(p<0.05)$. This agrees with the findings of Rahman and Hiepe (2002), where highly significant difference was reported between active SLE patients with reduced $\mathrm{C} 3$ level comparing with inactive SLE patients $(\mathrm{p}<0.001)$ and they 
concoluded that $\mathrm{C} 3$ provides the best assessment of disease activity in patients with SLE ${ }^{(27)}$.

On other hand some authors observed that C3 level was low in active stage of SLE especially during clinical exacerbation but its concentration was often normal in mild to moderate active stage ${ }^{(\mathbf{2 8})}$.

The present study showed a statistically significant decrease in level of serum complement (C4) in patients with SLE activity. Level of $\mathrm{C} 4$ concentration was lower in the active groups than in the inactive group of SLE. Similar results were reported by ${ }^{(25)}$.

Plasma levels of C3 and C4 were significantly decreased on comparing SLE patients to healthy normal subjects. Significant decrease in their levels was also found on comparing active SLE patients with patients in remission.

Inspite of many years of study of the SLE, the pathology or disease process in systemic lupus erythematosus remains unclear. Various laboratory tests were used for detection of the activity of the disease as ESR, plasma complements concentrations, and formation of autoantibodies ${ }^{(29)}$. The present study showed significant decrease in $\mathrm{RBC}, \mathrm{WBC}$ and platelet counts in patients with active SLE compared to patients in remission, as well as, to the healthy controls. Decreased RBC count could be explained by impaired renal function with decreased erythropoietin formation, and also due to poor general condition, cachexia and anorexia, in addition to bone marrow suppression by aggressive cytotoxic therapy (28).

Leucopenia in SLE patients occurs as part of drug toxicity-induced medullary hypoplasia. Also, it may be due to disease activity, bone marrow failure, peripheral destruction and sepsis. The most common mechanism of thrombocytopenia in SLE patients is believed to be increased RBCs, platelets clearance mediated by anti-platelet auto-antibodies ${ }^{(29)}$. ESR was significantly higher on comparing active SLE patients to patients in remission and healthy controls, and was significantly higher on comparing patients in remission to controls. This could be attributed to reduction of their synthesis and, also, their consumption in immune complex formation. These results indicated that complement dysfunction may be an important factor in the pathophysiology of SLE $^{(29)}$.
Conclusion: Dyslipidemia in SLE includes elevated levels of total cholesterol, TG, and LDL and decreased level of HDL. Elevation of TC, TG, LDL and decrease HDL are considered an independent risk factor for CVD share in premature atherosclerosis in these patients. Some SLE complication and disease activity contributes to dyslipidemia and hence cardiovascular risk associated with SLE.

\section{References}

1. Edworthy SM (2005): Clinical manifestations of systemic lupus erytheromatosus In Kelleys Textbook of Rheumatology, $7^{\text {th }}$ ed; chapter 75 .

2. Yukovich M, Vostretsova K, Chen W, Avina- Zubieta JA(2014): Overall and cause- specific mortality in patients with systemic lupus erythematosus: a metaanalysis of observational studies. Arthritis Care Res (Hoboken),66: 608- 16

3. Hollan I, Meroni PL, Ahearn JM, Cohen Tervaert JW, Curran S, Goodyear CS (2013): Cardiovascular disease in autoimmune rheumatic diseases. Autoimmune Rev., 12:1004-15.

4.Symmons DP and Gabriel SE (2011):Epidermology of CVD in rheumatic disease, with a focus on RA and SLE. Nat Rev Rheumatol. ,7(7): 399-408.

5. Maor I, Hayek T, Coleman $R$ and Aviram M (2013): Plasma LDL oxidation leads to its aggregation in the atherosclerotic apolipoprotein E-deficient mice. Arterioscler Thromb Vasc Biol.,17: 2995-3005.

6. Liu L, Zhang T, Ye Y, Zhang S, Chan TM (2014): Analysis of traditional cardiovascular factors in patients with SLE., 42(9):753-8.

7. Chong YB, Yap DY, Tang CS and Chan TM (2011): Dyslipidemia in patients with lupus nephritis. Nephrology,16: 511-17.

8. Bhakte SK and Sarker A (2016): Effect of serum lipoprotein (a) in menopausal women. Mymensingh Med J., 25(2): 255-60.

9. Borba EF and Bonfa E (2006): Dyslipoproteinemias in systemic lupus erythematous: Influence of disease, activity, and anticardiolipin antibodies. Lupus, 6(6): 533-39. 
10. Hochberg MC (1997): Revised criteria of the American College of Rheumatology for the classification of SLE. Modified from Hochberg, Arthritis Rheum., 40: 1725-34.

11. Liang HL, Socher SA, Larson MA, and Schur PH(1989): Reliability and validity of six systems for the clinical assessment of disease activity in systemic lupus erythematosus. Arthritis Rheum ., 32: 1107-18.

12. Flegg HM (1973): Ann Clin Biochem., 10-79.

13. Szekanecz $Z$ and Shoenfeld $Y$ (2006): Lupus and cardiovascular disease: the facts. Lupus, 15: 3-10.

14. Skaggs BJ, Hahn BH and McMahon M (2012): Accelerated atherosclerosis in patients with SLE; mechanism and management. Nature Reviews Rheumatology, 8: 214-23.

15. de Carvalho JF, Bonfa $E$ and Bobra EF (2008): Systemic lupus erytheromatosus and lupus dyslipoproteinemia. Autoimmunity Reviews, 7:246-50.

16. Roman MJ, Shanker BA, Davis A, Lockshin MD, Sammaritano $\mathrm{L}$ and CrowMK (2009): Prevalence and correlates of accelerated atherosclerosis in SLE. N Engle J Med., 349: 2399-2406.

17. Svenungsson E, Fei GZ, JensenUrstad K, de Faire U, Hamsten A and Frostegard J (2003): TNF-alfa: a link between hypertriglyceridaemia and inflammation in SLE patients with cardiovascular disease. Lupus, 12(6): 45461.

18. Batuca JR, Ames PRJ, Amaral M, Fava C, Isenberg DA and Alves JD (2007): Anti-atherogenic and antiinflammatory properties of high-density lipoprotein are affected by specific antibodies in systemic lupus erytheromatosus. Rheumatology, 48:2631.

19. Kashef S, Ghaedian MM, Rajaee A, Ghaderi A (2007): Dyslipoprpteinemia during the active course of SLE in association with anti-double-stranded DNA (anti-dsDNA) antibodies. Rheumatol. Int., 27: 235-41.
20. Melinda ZS, Peter $\mathbf{S}$ and Emess $\mathrm{K}$ (2017): Dyslipidemia in SLE patients. Immun Res. DOI. 10.1007/s12026-0168892-9.

21. Tam LS, Li EK and Tomlinson B (2006): Premature atherosclerosis in SLE: Pathogenesis and Therapeutic Considerations. Hong Kong J Nephrol., 8(2): 48-54.

22. Bobra EF, Bofna E, Vinagre CG, Ramires JA and Maranho RC (2001): Chylomicron metabolism is markedly altered in systemic lupus erytheromatosus. Arthritis and Rheum., 43:1033-40

23. Kaplan MJ (2009): Premature vascular damage in SLE: an imbalance of damage add repair? Translational Research., 154(2): 210-18.

24. Das S (1999): Disorders of lipid Metabolism. In: Sainani GS, editorin chief. API Text Book of Medicine. Mumbai, Association of Physicians of India. Six editions.

25. Mok CC, Ho LY, Leung HW, Wong LG (2010): Performance of anti-C1q, antinucleosome and anti-dsDNA antibodies for dectecting concurrent disese activity of SLE. Trans Res., 156:320-5.

26. Abd-Elsamad E, Mazen $M$, Nagwa $A$ and Yousry $M$ (2000): Urine neopterin as a parameter of disease activity in patients with systemic lupus erythematosus: comparison with antibodies to double stranded DNA and serum complement (C3 , C4): , thesis MD degree, Zagazig University .

27. HO A, Barr SG, Magder LS, Petri M (2003): A decrease in complement is associated with increased renal and hematologic activity in patients with systemic lupus erythematosus. Arthritis Rheum., 44: 2350-7.

28. Wang XY, Tang XQ, Huang YJ, Chen WY and Yu XQ (2012): Frequency of established cardiovascular disease and its risk factors in Chinese patients with SLE. Clin Rheumatol., 31(4): 669-75.

29. Rahman A, Hiepe F. (2002): AntiDNA antibodies - overview of assays and clinical correlations. Lupus, 11(12): 770773. 
Farag Khalil et al. 